\title{
Retraction Note to: Electrical Transmission between Mammalian Neurons is Supported by a Small Fraction of Gap Junction Channels
}

\author{
Sebastian Curti · Gregory Hoge • James I. Nagy • \\ Alberto E. Pereda
}

Published online: 20 July 2014

(C) Springer Science+Business Media New York 2014

Retraction Note to: J Membrane Biol (2012) 245:283-290 DOI 10.1007/s00232-012-9449-z

The article, Electrical Transmission between Mammalian Neurons is Supported by a Small Fraction of Gap Junction Channels, published in Journal of Membrane Biology (2012) 245:283-290, DOI: 10.1007/s00232-012-9449-z has been retracted by the Editor-in-Chief due to duplicate publication. The data set presented in the article was previously published in the journal article Synergy between Electrical Coupling and Membrane Properties Promotes Strong Synchronization of Neurons of the Mesencephalic Trigeminal Nucleus in the Journal of Neuroscience, 28 March, 2012 32(13):4341-4359, DOI: 10.1523/JNEUR OSCI.6216-11.2012.

The online version of the original article can be found under doi: $10.1007 / \mathrm{s} 00232-012-9449-\mathrm{z}$.

S. Curti $(\square)$

Facultad de Medicina, Departamento de Fisiología, Laboratorio de Neurofisiología Celular, Universidad de la República,

Gral. Flores 2125, Montevideo 11800, Uruguay

e-mail: scurti@fmed.edu.uy

G. Hoge · A. E. Pereda $(\bowtie)$

Dominick P. Purpura Department of Neuroscience, Albert

Einstein College of Medicine, Bronx, NY 10461, USA

e-mail: alberto.pereda@einstein.yu.edu

\section{J. I. Nagy}

Department of Physiology, University of Manitoba,

Winnipeg, Manitoba R3EOJ9, Canada 